\title{
Pooled molecular occurrence of Mycoplasma gallisepticum and Mycoplasma synoviae in poultry: A systematic review and meta-analysis
}

\author{
Miguel Angel Chaidez-Ibarra ${ }^{1}$, Diana Zuleika Velazquez ${ }^{1}$, Idalia Enriquez-Verdugo ${ }^{1}$, \\ Nohemi Castro del Campo ${ }^{1}$, Miguel Angel Rodriguez-Gaxiola ${ }^{1}$, Arnulfo Montero-Pardo ${ }^{1}$, \\ Daniel Diaz ${ }^{1}$, and Soila Maribel Gaxiola ${ }^{1}$ \\ ${ }^{1}$ Universidad Autonoma de Sinaloa
}

July 21, 2021

\begin{abstract}
Worldwide, Mycoplasma gallisepticum (MG) and M. synoviae (MS) are the main agents responsible for chronic respiratory disease in poultry. Therefore, we conducted a systematic review and meta-analysis to estimate their occurrence. We searched electronic databases to find peer-reviewed publications reporting the molecular detection of MG and MS in poultry and used meta-analysis to estimate their pooled occurrence (combined flock and individual), aggregating results at the regional and national levels. We performed a subgroup meta-analysis for subpopulations (broilers, layers, breeders, and diverse poultry including turkeys, ducks, and ostriches) and used meta-regression with categorical modifiers. We retrieved 2,294 publications from six electronic databases and included 85 publications from 33 countries that reported 62 studies with 22,162 samples for MG and 48 studies with 26,413 samples for MS. The pooled occurrence was $38.4 \%$ (95\% CI: 23.5-54.5) for MS and $27.0 \%$ (20.4-34.2) for MG. Among regions, Europe and Central Asia had the lowest occurrence for both pathogens, while MG and MS were highly prevalent in South Asia and sub-Saharan Africa, respectively. MG occurrence was higher in Algeria, Saudi Arabia, and Sudan, whereas China, Egypt, and Ethiopia reported a higher occurrence of MS. MS and MG were more prevalent in the breeders and layers $(62.6 \%$ and $31.2 \%$, respectively) than in diverse poultry. The year of publication, the sample size, and the level of ambient air pollution (measured indirectly by PM2.5) were associated with the occurrence of both mycoplasmas. Our study revealed a high and heterogeneous occurrence of MG and MS and justifies the need for an early detection and improved control measures to reduce the spread of these pathogens.
\end{abstract}

\section{Hosted file}

Ms Chaidez.docx available at https://authorea.com/users/426727/articles/531140-pooledmolecular-occurrence-of-mycoplasma-gallisepticum-and-mycoplasma-synoviae-in-poultry-asystematic-review-and-meta-analysis 

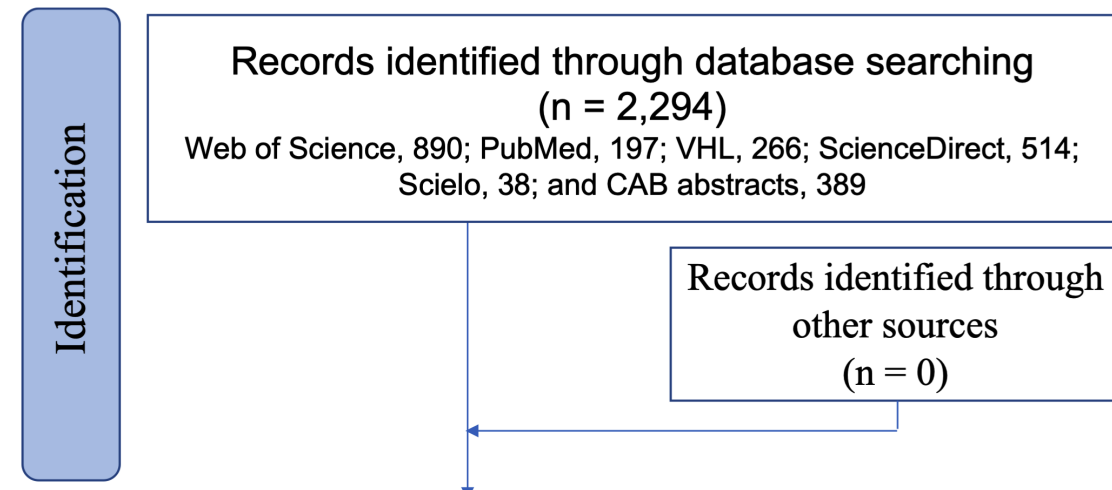
Scielo, 38; and CAB abstracts, 389
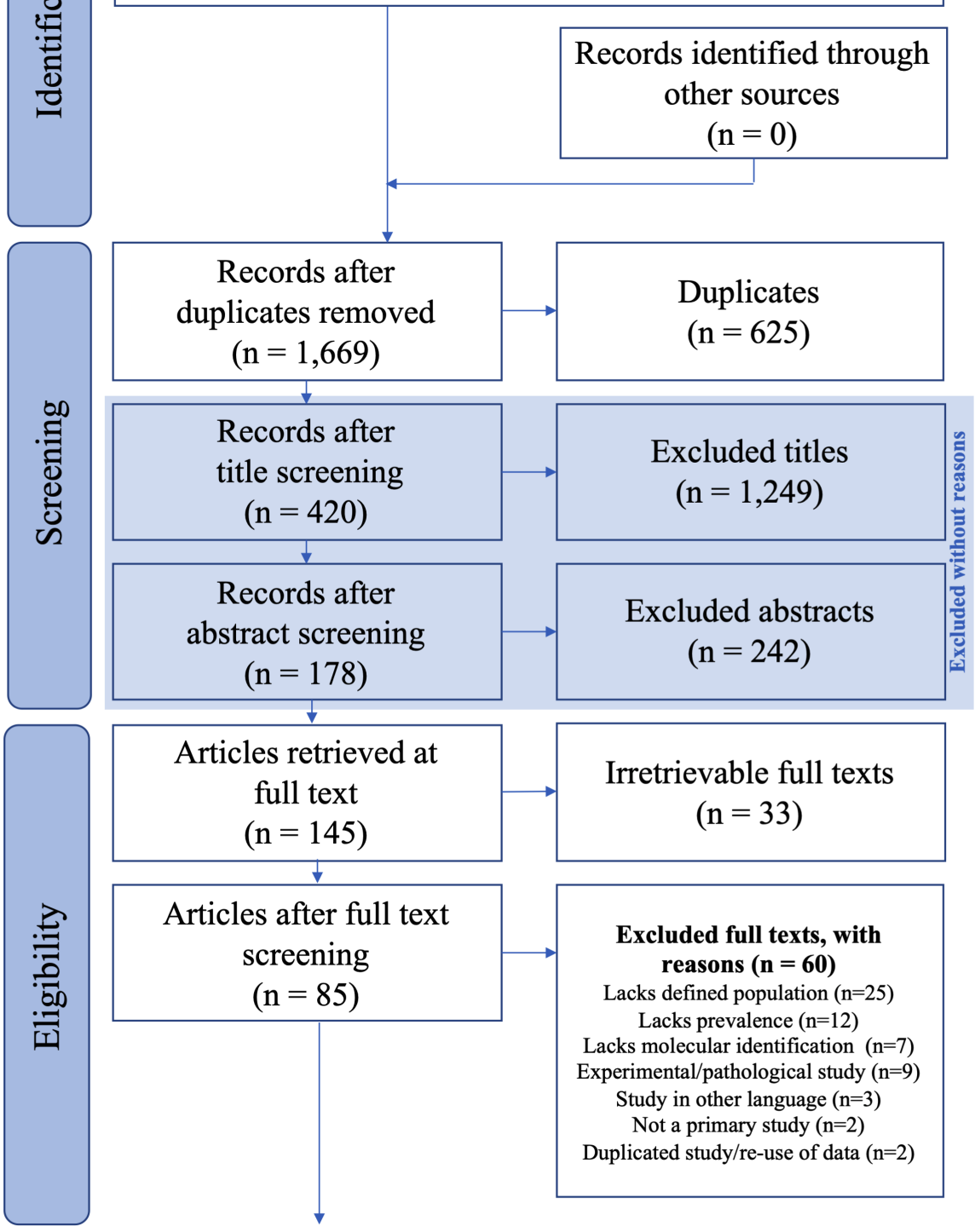

Articles after full text screening $(\mathrm{n}=85)$

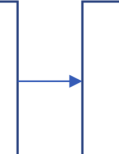

Excluded full texts, with reasons $(n=60)$

Lacks defined population $(\mathrm{n}=25)$ Lacks prevalence $(\mathrm{n}=12)$ Lacks molecular identification $(n=7)$ Experimental/pathological study $(\mathrm{n}=9)$

Study in other language $(n=3)$

Not a primary study $(\mathrm{n}=2)$

Duplicated study/re-use of data $(n=2)$

Articles included in quantitative synthesis $(\mathrm{n}=85)$

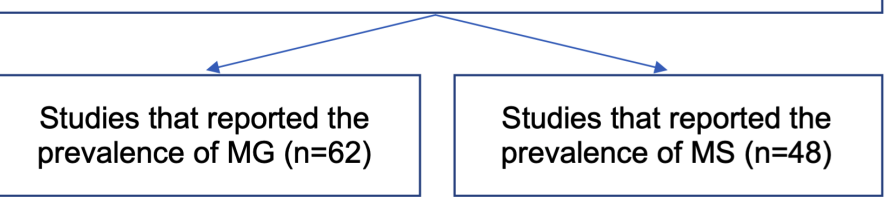


a
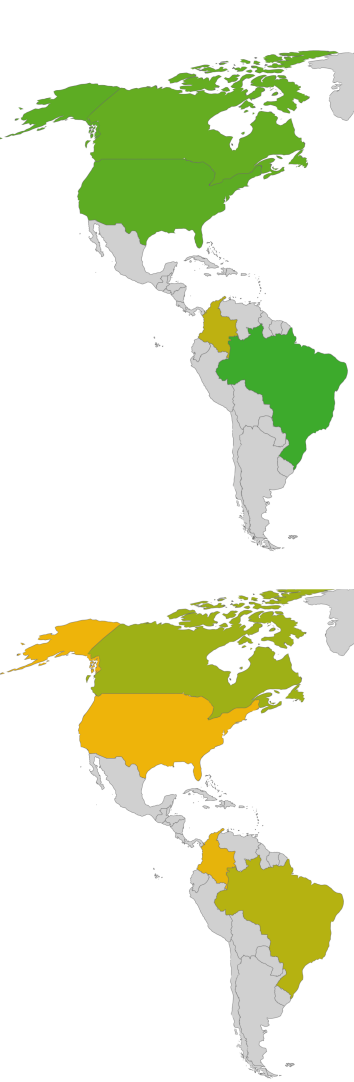

b $\odot$ M. gallisepticum

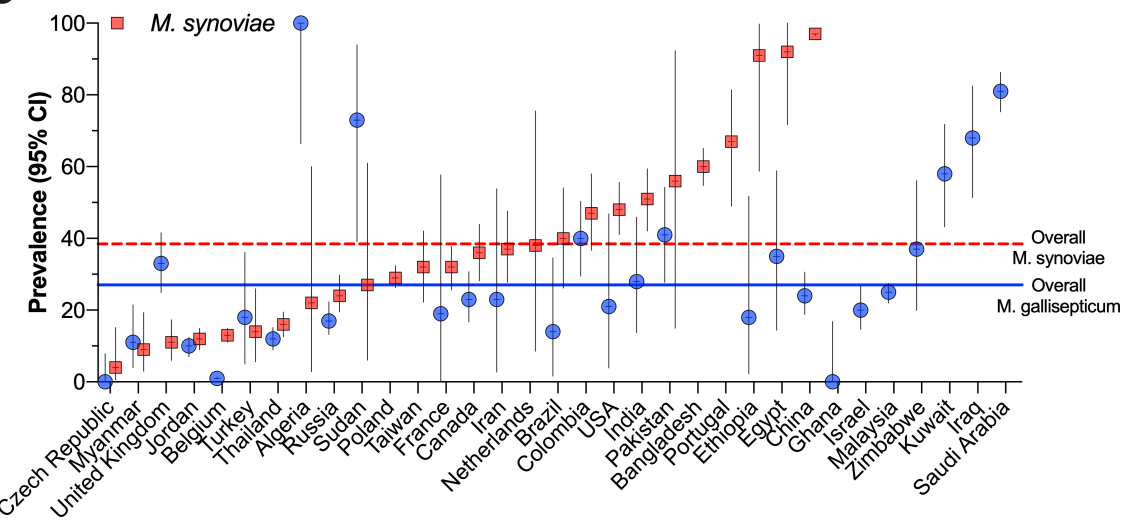

M. gallisepticum

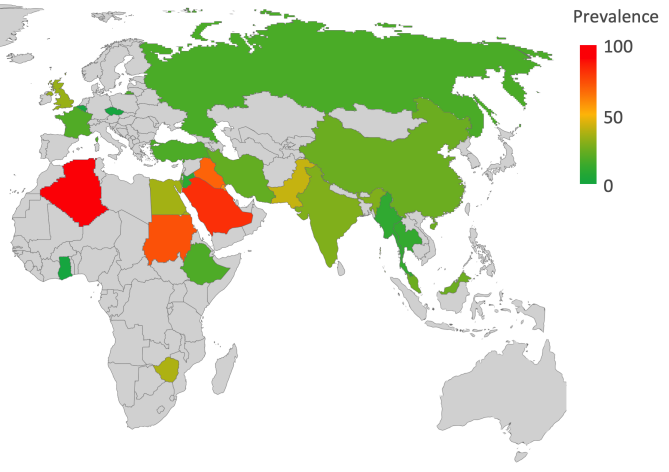

M. synoviae

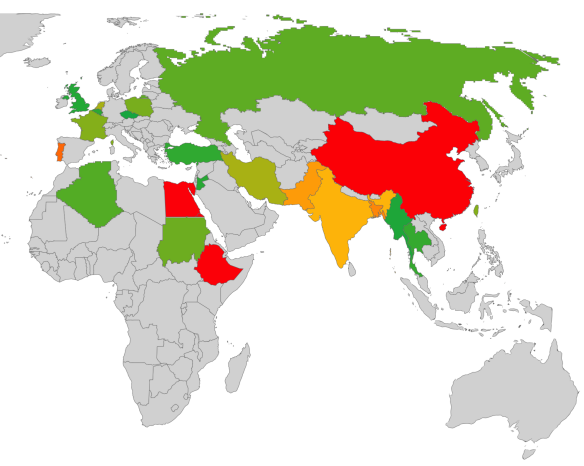



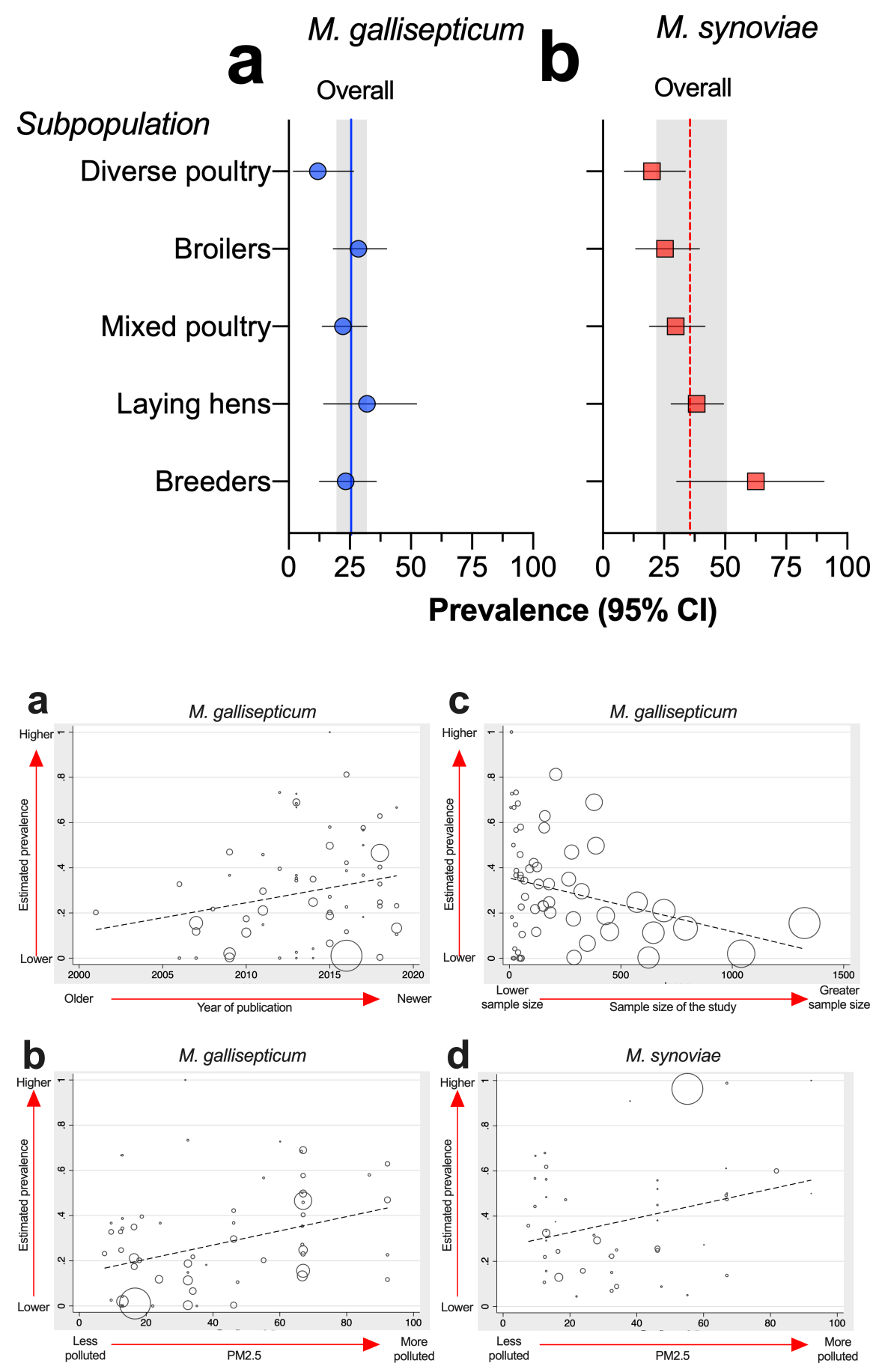

\section{Hosted file}

Table 1. docx available at https://authorea.com/users/426727/articles/531140-pooled-molecularoccurrence-of-mycoplasma-gallisepticum-and-mycoplasma-synoviae-in-poultry-a-systematicreview-and-meta-analysis

Hosted file 
Table 2.docx available at https://authorea.com/users/426727/articles/531140-pooled-molecularoccurrence-of-mycoplasma-gallisepticum-and-mycoplasma-synoviae-in-poultry-a-systematicreview-and-meta-analysis 